\title{
Investigation of the effect of body mass index (BMI) on semen parameters and male reproductive system hormones
}

\author{
Mehmet Zeynel Keskin ${ }^{1}$, Salih Budak ${ }^{1}$, Evrim Emre Aksoy ${ }^{2}$, Cem Yücel $^{1}$, Serkan Karamazak ${ }^{1}$, \\ Yusuf Ozlem Ilbey ${ }^{1}$, Zafer Kozacioğlu ${ }^{1}$ \\ ${ }^{1}$ Tepecik Training and Research Hospital, Izmir, Turkey; \\ ${ }^{2}$ Kırkağaç State Hospital, Manisa, Turkey.
}

\begin{abstract}
Summary Aim: To evaluate the effects of body mass index (BMI) ratio on semen parameters and serum reproductive hormones.

Materials and methods: The data of 454 patients who prsented to male infertility clinics in our hospital between 2014 and 2015 were analyzed retrospectively. Weight, height, serum hormone levels and semen analysis results of the patients were obtained. BMI values were calculated by using the weight and height values of the patients and they were classified as group 1 for BMI values $\leq 25 \mathrm{~kg} / \mathrm{m}^{2}$, as group 2 for BMI values $25-30$ $\mathrm{kg} / \mathrm{m}^{2}$ and as group 3 for BMI values $\geq 30 \mathrm{~kg} / \mathrm{m}^{2}$.

Results: The mean values of BMI, semen volume, concentration, total motility, progressive motility, total progressive motile sperm count (TPMSC), normal morphology according to Kruger, head abnormality, neck abnormality, tail abnormality, FSH, LH, prolactin, T/E2, total testosterone and estradiol parameters of the patients were considered.

Patients were divided according to BMI values in Group 1 $(n=165)$, Group $2(n=222)$ and Group $3(n=56)$.

There was no statistically significant difference in terms of all variables between the groups.

Conclusions: We analyzed the relationship between BMI level and semen parameters and reproductive hormones, demonstrating no relationship between BMI and semen parameters. In our study, BMI does not affect semen parameters although it shows negative correlation with prolactin and testosterone levels.
\end{abstract}

KEY WORDS: Infertility; BMI; Semen parameters; Reproductive hormones.

Submitted 18 May 2016; Accepted 19 August 2016

\begin{abstract}
INTRODUCTION
Being overweight and obesity are among the most significant health problems in our era. World Health Organization (WHO) described as overweight a patient with body mass index (BMI) $\geq 25 \mathrm{~kg} / \mathrm{m}^{2}$ and as obese a patient with BMI $\geq$ $30 \mathrm{~kg} / \mathrm{m}$. According to WHO data, $35 \%$ of the young patients, who are in their twenties, are overweight and $11 \%$ of them are obese (1). It was reported that the overweight and obesity incidence dramatically increased in developed countries in last 30 years (2).

Infertility is another health problem affecting $15 \%$ of the couples in developed countries (3). A significant decrease in the sperm quality was shown by studies conducted in last 25 years $(4,5)$. The reason of this decrease aroused interest and it became a subject for research. Especially, its relation with the obesity was analyzed in a
\end{abstract}

number of studies and in some studies this decrease was found as associated to the increase in obesity prevalence (2). But, there is not a consensus in the literature and contradictory results were published. In this study, we analyzed the effect of BMI on semen parameters and the relationship with reproductive hormone levels.

\section{Materials AND METHOdS}

The data of 454 patients who presented to male infertility clinics in our hospital between 2014 and 2015 were analyzed retrospectively. Weight, height, serum hormone levels and semen analysis results of the patients were considered. BMI values were calculated by using the weight and height values of the patients and they were classified as Group 1 for BMI values $\leq 25 \mathrm{~kg} / \mathrm{m}^{2}$, as Group 2 for BMI values $25-30 \mathrm{~kg} / \mathrm{m}^{2}$ and as Group 3 for BMI values $\geq 30 \mathrm{~kg} / \mathrm{m}^{2}$.

Semen analysis was performed after a 3-5 days of sexual abstinence. Semen analysis was performed according to WHO 2010 criteria (semen volume $\geq 1.5 \mathrm{ml}$; sperm concentration $\geq 15 \times 106 / \mathrm{ml}$; total motility $\geq 40 \%$, progressive motility $\geq 32 \%$ and morphology $\geq 4 \%$ ). After 5-30 minutes of sample collection, the analysis was performed after the sample was liquefied. For the microscopic examination in semen analysis, phase contrast light microscope was used and the examination was performed with 10 x 20 magnification. For sperm concentration, Makler counting chamber was used and the sperm count (concentration) was found in million/ml with the sperm count in 10 squares in a 100 square area. Motility was evaluated in 3 Groups as linear progressive motility, non-progressive motility and immotility. For the morphological examination, semen sample which was dropped on slides, washed with $70 \%$ alcohol previously, according to sperm concentration were dried with 45 degrees angle. Then, it was stained with DiffQuick kit and at least 200 sperm were analyzed under immersion oil with 100X objective and the percentage of the sperm having normal morphology was determined.

For the hormone levels, blood sample was collected in the morning before 10.00 a.m. Hormone analysis was performed with Roche Hitachi Cobase 601 equipment and by using microparticle enzyme immunoassay method. FSH, $\mathrm{LH}$, prolactin, total testosterone and estradiol levels were analyzed. The statistical analysis was performed with IBM Statistical Package for Social Sciences (SPSS) Version 22.0

No conflict of interest declared. 


\begin{tabular}{|c|c|c|c|c|}
\hline \multirow[b]{2}{*}{ Parameter } & \multicolumn{4}{|c|}{ BMI } \\
\hline & $<25.0 \mathrm{~kg} / \mathrm{m}^{2}$ & $25.0-30.0 \mathrm{~kg} / \mathrm{m}^{2}$ & $>30.0 \mathrm{~kg} / \mathrm{m}^{2}$ & p value \\
\hline$\overline{B M I}\left(\mathrm{~kg} / \mathrm{m}^{2}\right)$ & & & & \\
\hline Minimum & 18.78 & 25.01 & 30.04 & \\
\hline Maximum & 24.98 & 29.98 & 43.55 & \\
\hline Mean & 22.65 & 27.06 & 33.09 & \\
\hline Std. Dev. & 1.69 & 1.35 & 3.44 & \\
\hline Volume (mL) & & & & 0.330 \\
\hline Minimum & 0 & 0 & 0 & \\
\hline Maximum & 11 & 8 & 8 & \\
\hline Mean & 2.88 & 2.69 & 2.58 & \\
\hline Std. Dev. & 1.71 & 1.67 & 1.65 & \\
\hline Concentration $\left(10^{6} / \mathrm{mL}\right)$ & & & & 0.576 \\
\hline Minimum & 0 & 0 & 0 & \\
\hline Maximum & 168 & 170 & 140 & \\
\hline Mean & 33.28 & 35.56 & 33.74 & \\
\hline Std. Dev. & 36.91 & 36.29 & 35.59 & \\
\hline Total motility (\%) & & & & 0.754 \\
\hline Minimum & 0 & 0 & 0 & \\
\hline Maximum & 85 & 85 & 90 & \\
\hline Mean & 46.34 & 49.76 & 47.63 & \\
\hline Std. Dev. & 25.29 & 22.22 & 27.26 & \\
\hline Progressive motility (\%) & & & & 0.694 \\
\hline Minimum & 0 & 0 & 0 & \\
\hline Maximum & 80 & 94 & 80 & \\
\hline Mean & 30.15 & 31.94 & 30.66 & \\
\hline Std. Dev. & 21.89 & 21.55 & 22.91 & \\
\hline TPMSC (Million) & & & & 0.790 \\
\hline Minimum & 0 & 0 & 0 & \\
\hline Maximum & 352.8 & 361.08 & 220 & \\
\hline Mean & 40.66 & 44.40 & 41.97 & \\
\hline Std. Dev. & 59.97 & 62.83 & 56.67 & \\
\hline Normal morphology (Kruger) (\%) & & & & 0.554 \\
\hline Minimum & 0 & 0 & 0 & \\
\hline Maximum & 10 & 9 & 7 & \\
\hline Mean & 2.43 & 2.60 & 2.26 & \\
\hline Std. Dev. & 2.23 & 2.12 & 2.00 & \\
\hline Head abnormality (\%) & & & & 1.000 \\
\hline Minimum & 0 & 0 & 0 & \\
\hline Maximum & 100 & 91 & 86 & \\
\hline Mean & 50.16 & 51.75 & 48.20 & \\
\hline Std. Dev. & 39.93 & 38.41 & 40.82 & \\
\hline Neck abnormality (\%) & & & & 0.937 \\
\hline Minimum & 0 & 0 & 0 & \\
\hline Maximum & 14 & 14 & 14 & \\
\hline Mean & 5.72 & 6.15 & 6 & \\
\hline Std. Dev. & 5.12 & 4.89 & 5.29 & \\
\hline Tail abnormality (\%) & & & & 0.561 \\
\hline Minimum & 0 & 0 & 0 & \\
\hline Maximum & 11 & 13 & 14 & \\
\hline Mean & 4.16 & 4.66 & 3.80 & \\
\hline Std. Dev. & 3.86 & 3.94 & 4.02 & \\
\hline$\overline{\mathrm{FSH}}(\mathrm{mlU} / \mathrm{mL})$ & & & & 0.299 \\
\hline Minimum & 1.56 & 1.57 & 1.68 & \\
\hline Maximum & 31 & 44.72 & 17.15 & \\
\hline Mean & 3.42 & 2.76 & 2.18 & \\
\hline Std. Dev. & 5.58 & 2.18 & 3.74 & \\
\hline$\overline{\mathrm{LH}}(\mathrm{mlU} / \mathrm{mL})$ & & & & 0.452 \\
\hline Minimum & 2 & 1.63 & 2.02 & \\
\hline Maximum & 14.63 & 19.57 & 16.87 & \\
\hline Mean & 5.61 & 5.29 & 6.04 & \\
\hline Std. Dev. & 2.74 & 5.72 & 3.22 & \\
\hline Prolactin $(\mathrm{ng} / \mathrm{mL})$ & & & & 0.018 \\
\hline Minimum & 3.35 & 2.98 & 5.83 & \\
\hline Maximum & 27.85 & 49.29 & 27.04 & \\
\hline Mean & 11.44 & 9.87 & 10.88 & \\
\hline Std. Dev. & 5.51 & 5.84 & 4.37 & \\
\hline$\overline{\mathrm{T} / \mathrm{E} \text { ratio (\%) }}$ & & & & 0.815 \\
\hline Minimum & 6.98 & 2.05 & 8.31 & \\
\hline Maximum & 22.16 & 39.13 & 14.87 & \\
\hline Mean & 11.82 & 15.49 & 11.59 & \\
\hline Std. Dev. & 8.26 & 9.77 & 4.63 & \\
\hline Testosterone (ng/dL) & & & & 0.001 \\
\hline Minimum & 9.1 & 4.31 & 147.10 & \\
\hline Maximum & 851.7 & 856 & 676.20 & \\
\hline Mean & 488.32 & 398.20 & 377.61 & \\
\hline Std. Dev. & 175.13 & 139.71 & 113.36 & \\
\hline$\overline{\text { Estradiol (pg/mL) }}$ & & & & 0.270 \\
\hline Minimum & 16.32 & 7.21 & 32.76 & \\
\hline Maximum & 44.24 & 160.30 & 57.29 & \\
\hline Mean & 29.88 & 34.93 & 45.02 & \\
\hline Std. Dev. & 9.87 & 37.12 & 17.34 & \\
\hline
\end{tabular}

Table 1.

Mean volues of data and $p$ values according to $\mathrm{BMI}$ groups.

programme. A value of $\mathrm{p}<0.05$ was accepted as statistically significant.

\section{Results}

The mean values of BMI, semen volume, concentration, total motility, progressive motility, total progressive motile sperm count (TPMSC), normal morphology according to Kruger, head abnormality, neck abnormality, tail abnormality, FSH, LH, prolactin, T/E2, total testosterone and estradiol parameters of the patients are shown in Table 1. Patients were divided according to BMI values in Group 1 ( $\mathrm{n}=$ 165), Group $2(\mathrm{n}=222)$ and Group 3 $(\mathrm{n}=56)$. There was no statistically significant difference in semen parameters between the groups. BMI ratio do not affect semen parameters but it shows negative correlation with prolactin and total testosterone.

\section{Discussion}

The effect of obesity on semen parameters is multifactorial and it was tried to be explained with different pathophysiological mechanisms $(6,7)$.

The fact that testosterone is aromatized to estradiol (E2) in fat tissue (8), the decrease in sex hormone binding globulin (SHBG) levels (9), the suppression of luteinizing hormone (LH) secretion with the increase of endorphin levels (10), hyperinsulinemia and hyperlipidemia (11) were found as responsible for this relationship, although there are contradictory results in the literature.

In a meta-analysis conducted by MacDonald et al., no relationship between semen parameters and BMI was detected (12). Moreover, in other similar original studies, this relationship was not found $(13,14)$. On the contrary, in a meta-analysis conducted by Sermondade et al., a negative relationship between BMI and semen parameters was detected (7). There are also original studies reporting similar results (15-17). While a statistically significant negative relationship was detected between BMI and semen volume, concentration and motility in a comprehensive cohort study including 10665 patients conducted by Belloc 
et al., no relationship with morphology was detected (18). In another study with 42 patients conducted by Leisegang et al., it was reported that BMI level and sperm concentration are negatively correlated and no correlation was detected with motility and morphology (19). In a cohort study, which Stewart et al. conducted with 225 fertile male patients, it was reported that BMI and sperm count are negatively correlated (20). In our study, no statistically significant relationship was found between BMI level and semen parameters. In a recent study, on the other hand, the relationship between BMI and semen parameters and reproductive hormone levels was analyzed and a statistically significant negative relationship between BMI and semen volume, SHBG and total Testosterone (T) level was detected (21). In the study conducted by Relwani et al., it was reported that BMI level does not affect semen parameters but it statistically significantly decreases T, SHBG and free $T$ level (22). In the literature, there is a general consideration that obesity especially decreases total testosterone and SHBG levels but it is partially correlated to free testosterone levels $(16,23)$. In our study, we observed that when BMI level is high, prolactin and total testosterone levels are significantly lower.

\section{Conclusions}

In our study, when we analyzed the relationship between BMI level and semen parameters and reproductive hormones, no relationship was detected between BMI and semen parameters. On the contrary BMI level shows a negative correlation with prolactin and testosterone levels. However, to reveal the relationship between BMI and male infertility, large, randomized and prospective studies are needed.

\section{REFERENCES}

1. Joint WHO/FAO Expert Consultation. Diet, nutrition and the prevention of chronic diseases. WHO Technical Report Series 916. World Health Organization, Geneva; 2003.

2. Finucane MM, Stevens GA, Cowan MJ, et al. Global Burden of Metabolic Risk Factors of Chronic Diseases Collaborating Group (Body Mass Index). National, regional, and global trends in bodymass index since 1980: systematic analysis of health examination surveys and epidemiological studies with 960 country-years and 9.1 million participants. Lancet. 2011; 377:557-567.

3. Eisenberg ML, Kim S, Chen Z, et al. The relationship between male BMI and waist circumference on semen quality: data from the LIFE study. Hum Reprod. 2014; 29:193-200.

4. Carlsen E, Giwercman A, Keiding N, Skakkebaek NE. Evidence for decreasing quality of semen during past 50 years. Br Med J. 1992; 305:609-613.

5. Swan SH, Elkin EP. Declining semen quality: can the past inform the present? Bioessays 1999; 21:614-621.

6. Eisenberg ML, Kim S, Chen Z, et al. The relationship between male BMI and waist circumference on semen quality: data from the LIFE study. Hum Reprod. 2015; 30:493-4.

7. Sermondade N, Faure C, Fezeu L, et al. BMI in relation to sperm count: an updated systematic review and collaborative meta-analysis. Hum Reprod Update. 2013; 19:221-231.

8. Schneider G, Kirschner MA, Berkowitz R, Ertel NH. Increased estrogen production in obese men. J Clin Endocrinol Metab. 1979; 48:633-638

9. Stellato RK, Feldman HA, Hamdy O, et al. Testosterone, sex hormone-binding globulin, and the development of type 2 diabetes in middle-aged men: prospective results from the Massachusetts male aging study. Diabetes Care. 2000; 23:490-494.

10. Blank DM, Clark RV, Heymsfield SB, et al. Endogenous opioids and hypogonadism in human obesity. Brain Res Bull. 1994; 34:571-574.

11. Lampiao F, du Plessis SS. Insulin and leptin enhance human sperm motility, acrosome reaction and nitric oxide production. Asian J Androl. 2008; 10:799-807.

12. MacDonald AA, Herbison GP, Showell M, Farquhar CM. The impact of body mass index on semen parameters and reproductive hormones in human males: a systematic review with meta-analysis. Hum Reprod Update. 2010; 16:293-311.

13. Aggerholm AS, Thulstrup AM, Toft G, et al. Is overweight a risk factor for reduced semen quality and altered serum sex hormone profile? Fertil Steril. 2008; 90:619-626.

14. Li Y, Lin H, Ma M, et al. Semen quality of 1346 healthy men, results from the Chongqing area of southwest China. Hum Reprod. 2009; 24:459-469.

15. Jensen TK, Andersson AM, Jørgensen N, et al. Body mass index in relation to semen quality and reproductive hormones among 1,558 Danish men. Fertil Steril. 2004; 82:863-870.

16. Erdemir F. Relationship Between Obesity and Male Infertility. J Clin Anal Med. 2013; 4:76-82.

17. Hofny ER, Ali ME, Abdel-Hafez HZ, et al. Semen parameters and hormonal profile in obese fertile and infertile males. Fertil Steril. 2010; 94:581-584

18. Belloc S, Cohen-Bacrie M, Amar E, et al. High body mass index has a deleterious effect on semen parameters except morphology: results from a large cohort study. Fertil Steril. 2014; 102:1268-73.

19. Leisegang K, Bouic PJ, Menkveld R, Henkel RR. Obesity is associated with increased seminal insulin and leptin alongside reduced fertility parameters in a controlled male cohort. Reprod Biol Endocrinol. 2014; 12:34:2-12.

20. Stewart TM, Liu DY, Garrett C, et al. Associations between andrological measures, hormones and semen quality in fertile Australian men: inverse relationship between obesity and sperm output. Hum Reprod. 2009; 24:1561-1568.

21. Ehala-Aleksejev K, Punab M. The different surrogate measures of adiposity in relation to semen quality and serum reproductive hormone levels among Estonian fertile men. Andrology. 2015; 3:225-234.

22. Relwani $R$, Berger D, Santoro N, et al. Jindal Semen parameters are unrelated to BMI but vary with SSRI use and prior urological surgery. Reprod Sci. 2011; 18:391-7.

23. Allen NE, Appleby PN, Davey GK, Key TJ. Lifestyle and nutritional determinants of bioavailable androgens and related hormones in British men. Cancer Causes Control. 2002; 13:353-63.

\section{Correspondence}

Mehmet Zeynel Keskin, MD (Corresponding Author) zeynel_akd@hotmail.com

Salih Budak, MD - salihbudak1977@gmail.com

Cem Yücel, MD - meclecuy@hotmail.com

Serkan Karamazak, MD - drkaramazak@hotmail.com

Yusuf Ozlem Ilbey, MD - ozlemyusufilbey@hotmail.com

Zafer Kozacıoğlu, MD - drzafko@hotmail.com

Tepecik Training and Research Hospital, Izmir, Turkey

Evrim Emre Aksoy, MD - dreaksoy@yahoo.com

Kırkağaç State Hospital, Manisa, Turkey 